4 Cogosic FINAL REPORT Project Armis No. 4191

\section{The Ultra-Rapid \\ Chilling of Lamb \\ Carcasses}
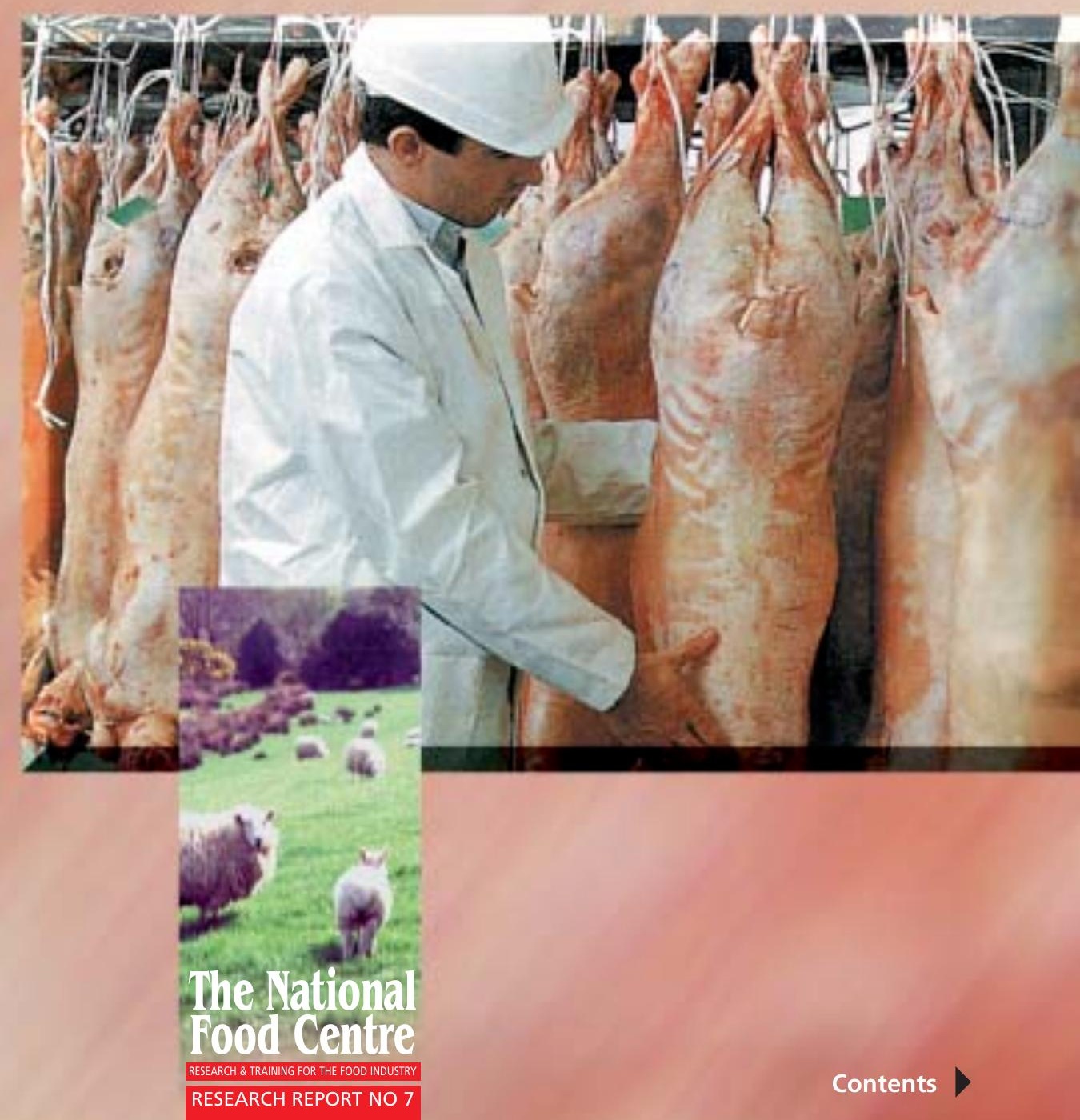

Contents $>$ 


\section{THE ULTRA-RAPID}

\section{CHILLING}

OF

\section{LAMB CARCASSES}

\section{Authors}

Brian Mc Geehin, B.E., M.I.E.I.

James. J. Sheridan, M.A., M. Sc., Ph.D.

The National Food Centre, Dunsinea, Castleknock, Dublin 15

Francis Butler B.E., M.B.A.

Department of Agricultural \& Food Engineering, University College Dublin, Earlsfort Terrace, Dublin 2

Teagasc acknowledges with gratitude grant aid under the Food Sub-Programme (Sub-measure 3 (ii) - Institutional R\&D) of the Operational Programme for Industrial Development.

The programme is managed by the Department of Agriculture and Food supported by EU and national funds.

ISBN 1841700029

January 1999

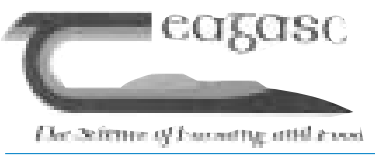

Teagasc 19 Sandymount Avenue Ballsbridge Dublin 4 


\section{CONTENTS}

Summary

Introduction

Methods

3

Chilling investigations

Meat $\mathrm{pH}$ investigations

4

Use of lower temperatures and increased air speeds 5

Use of low voltage stimulation 6

Optimisation of the ultra-rapid chilling process 8

Effect of method of stunning on meat $\mathrm{pH}$ values 9

Effects of age, weight and season on meat $\mathrm{pH}$ values

Conclusions

List of publications from this research project 


\section{SUMMARY}

The practice in Irish commercial abattoirs is to chill lamb carcasses for a period of approximately 16 hours at $2-4^{\circ} \mathrm{C}$, at which stage the core temperature of the carcass has reached $7^{\circ} \mathrm{C}$. Chilling in this manner is considered necessary because it is generally held that faster chilling leads to toughening of the meat. The objective of this work was to develop a continuous ultra-rapid chilling system for lambs which would reduce carcass chilling time without adversely affecting the quality of the meat.

- Ultra-rapid chilling rapidly reduced carcass temperature and so reduced throughput time from around 16 hours down to about 6 hours. This eliminated the need for overnight chilling and would allow lamb to be dispatched to European markets on the day of slaughter.

- Ultra-rapid chilling was applied without any negative impact on meat quality to lambs with an intermediate rate of $\mathrm{pH}$ fall and produced meat that was as tender as conventionally chilled meat.

- Evaporative weight losses in industry are approximately $2 \%$. By using ultra-rapid chilling and controlling relative humidity, these losses can be reduced to $1 \%$. 


\section{INTRODUCTION}

Rapid chilling of lambs has long been possible, but has generally been avoided because of fears of causing toughness. Meat may be toughened due to muscle cold shortening if low temperature and high $\mathrm{pH}$ conditions exist in pre-rigor musculature. Recent findings however, have shown that carcasses may be ultra-rapidly chilled without adversely affecting the tenderness of the meat (Sheridan, 1990).

The aim of this work was to develop a very fast chilling regime for Irish lamb carcasses. To apply these chilling rates in industry would mean that the need for overnight chilling would be eliminated and carcasses could be dispatched to market on the day of slaughter. This would mean that Irish export lambs could reach European markets one day earlier. The 16-hour chilling cycle currently used requires an overnight stay at the plant, with dispatch to overseas markets typically occurring the day after slaughter. As fresh lamb has a relatively short shelf life, the elimination of an overnight stay for the carcasses would be beneficial to their shelf life on continental markets.

Current chilling practice necessitates chilling to be carried out in batches. Lamb carcasses are loaded together into a chill room where they are cooled until they reach the desired temperature. A fundamental problem with batch chilling is uneven airflow, which results in different chilling rates among the carcasses. Consequences of this are differences in meat tenderness and varying weight losses within a batch. Rapid chilling would allow the use of a continuous line chilling with better uniformity and control of chilling rates.

There are also financial aspects to be considered. Average commercial weight losses during conventional chilling are about $2 \%$. Significant reductions in weight loss would have a major impact on profitability. Proper use of rapid chilling can provide these reductions. These experiments were carried out so that a recommendation could be made to industry on the feasibility of rapid chilling on lamb carcasses. 


\section{METHODS}

Measurements done on carcasses included temperature (during chilling), $\mathrm{pH}$, sarcomere length (to assess if cold shortening had taken place), $24 \mathrm{~h}$ weight losses and tenderness (instrumental and sensory analysis).

\section{Chilling investigations}

Three chilling experiments were conducted to investigate the feasibility of ultra-rapid chilling.

The first chilling trial used lower temperatures and increased airspeeds to speed up the rate of chilling. Investigations were carried out on the effects of three chilling regimes (conventional, intermediate and ultra-rapid) on lamb carcasses. Each chilling regime was of $24 \mathrm{~h}$ duration. The regimes were as follows: conventional - carcasses were held at $4^{\circ} \mathrm{C}$ with airspeed less than $0.2 \mathrm{~m} / \mathrm{s}$ throughout; intermediate - carcasses were held at $-2^{\circ} \mathrm{C}$ with an airspeed of $2.5 \mathrm{~m} / \mathrm{s}$ for $24 \mathrm{~h}$; ultra-rapid - carcasses were chilled for $3.5 \mathrm{~h}$ at $-20^{\circ} \mathrm{C}$ with an airspeed of $1.5 \mathrm{~m} / \mathrm{s}$ and then held at $4^{\circ} \mathrm{C}$ with airspeed less than $0.2 \mathrm{~m} / \mathrm{s}$ and high relative humidity for $20.5 \mathrm{~h}$. All lambs were then stored at $4^{\circ} \mathrm{C}$ until day 5 postmortem. A total of 12 carcasses was assigned to each chilling regime. Measurements carried out on the lamb loins (M. longissimus dorsi) on day 1 and day 5 included sensory analysis, shear meter assessment, sarcomere length, $\mathrm{pH}$, and weight loss at day 1 postmortem. The next trial examined the use of low voltage electrical stimulation with ultra-rapid chilling to minimise the occurrence of occasional tough carcasses. Twenty carcasses were chilled conventionally $\left(4^{\circ} \mathrm{C}, 0.2 \mathrm{~m} / \mathrm{s}, 24 \mathrm{~h}\right)$ and twenty carcasses were ultra-rapidly chilled $\left(-20^{\circ} \mathrm{C}, 1.5 \mathrm{~m} / \mathrm{s}, 3.5 \mathrm{~h}\right.$; followed by $4^{\circ} \mathrm{C}, 0.2 \mathrm{~m} / \mathrm{s}, 20.5 \mathrm{~h}$ ). Low voltage electrical stimulation (ES) was used on twenty of the carcasses. Four carcass muscles were tested to give a broader picture of the effect of chilling regimes on whole carcasses. Tenderness assessment was done on leg carcass muscles (M. biceps femoris, M. gluteus medius and M. semimembranosus) and on the loins (M. longissimus dorsi). 
The objective of the final trial was to optimise the ultra-rapid chilling process. Up to this point a single ultra-rapid chilling regime has been used consisting of chilling lambs at $-20^{\circ} \mathrm{C}$ for $3.5 \mathrm{~h}$ using an airspeed of $1.5 \mathrm{~m} / \mathrm{s}$ followed by $20.5 \mathrm{~h}$ at $4^{\circ} \mathrm{C}$. This regime was used because it was shown in the past to produce tender meat (Sheridan, 1990). The three possible variables of the chilling conditions are:

- air temperature

- airspeed

- duration of chilling.

These variables were examined to determine how changes affect tenderness and weight loss.

\section{Meat $\mathrm{pH}$ investigations}

The rate of development of rigor mortis in a carcass is determined by the rate of postmortem glycolysis. This, in turn, can be monitored by measuring meat $\mathrm{pH}$ at intervals after slaughter. In good quality meat the $\mathrm{pH}$ falls from about 7.0 at slaughter to about 5.5 in rigor muscle. The tenderness of ultrarapidly chilled meat has been linked to favourable meat $\mathrm{pH}$ values. High $\mathrm{pH}$ values in the early hours postmortem allows cold-shortening to take place. Some electric stunning methods can cause indirect electrical stimulation of muscles resulting in rapid $\mathrm{pH}$ fall; lambs stunned by captive bolt exhibit much less kicking during slaughter and consequently $\mathrm{pH}$ falls at a slower rate (Devine et al., 1984). A rapid rate of postmortem $\mathrm{pH}$ fall is important when using ultra-rapid chilling and so an experiment was carried out to determine if electrical stunning was indirectly stimulating the carcasses during slaughter. Eighteen lambs were slaughtered using 'head-only' electrical stunning and eighteen were slaughtered using captive bolt stunning and $\mathrm{pH}$ was measured in all lambs at various intervals postmortem. In order to better understand $\mathrm{pH}$ decline in lambs, a second $\mathrm{pH}$ experiment was carried out to determine whether age, weight, season, sex and ambient conditions influence the rate and magnitude of postmortem $\mathrm{pH}$ decline. Regression analysis of these factors may make it possible to predict $\mathrm{pH}$ fall 
in lamb and thereby estimate the individual electrical requirements of each lamb to give optimum $\mathrm{pH}$ fall.

For each month over a one year period, lambs were bought from farms locally in batches of eight and taken to The National Food Centre (NFC). In total 96 lambs were used. The age and weight of each lamb in a batch was recorded as well as $\mathrm{pH}$ measurements. Daily temperatures were obtained from Met Éireann.

\section{Use of lower temperatures and increased air speeds}

The results are shown in Table 1 . Shear meter values of less than 45

Newtons indicate meat of acceptable tenderness.

Table 1: The effect of chilling regime and time on the tenderness (Newtons) of lamb loins (M. longissimus dorsi)

\begin{tabular}{|lccc|}
\hline Time & Conventional & $\begin{array}{c}\text { Chilling regime } \\
\text { intermediate }\end{array}$ & Ultra-rapid \\
\hline 1 day & 33.6 & 35.6 & 32.5 \\
\hline 2 day & 34.9 & 36.1 & 35.3 \\
\hline 5 day & 34.3 & 40.2 & 36.0 \\
\hline
\end{tabular}

s.e.d. $=3.0$, d.f. $=30$

$\begin{array}{ll}\text { conventional } & 4^{\circ} \mathrm{C}, 0.2 \mathrm{~m} / \mathrm{s}, 24 \mathrm{~h} \\ \text { intermediate } & -2^{\circ} \mathrm{C}, 2.5 \mathrm{~m} / \mathrm{s}, 24 \mathrm{~h} \\ \text { ultra-rapid } & -20^{\circ} \mathrm{C}, 1.5 \mathrm{~m} / \mathrm{s}, 3.5 \mathrm{~h} \text {; followed by } 4^{\circ} \mathrm{C}, 0.2 \mathrm{~m} / \mathrm{s}, 20.5 \mathrm{~h}\end{array}$

There were no significant differences between any of the treatments over time. All loins were as tender after $24 \mathrm{~h}$ as they were after 5 days' storage. The degree of tenderness at $24 \mathrm{~h}$ may be a result of a rapid rate of $\mathrm{pH}$ decline in the first $4 \mathrm{~h}$ postmortem. The change in $\mathrm{pH}$ of carcass loins in all chilling regimes, from $1 \mathrm{~h}$ to $4 \mathrm{~h}$ postmortem, was from about 6.5 to 6.0. The muscle fibre sarcomere lengths were essentially the same (conventional $1.76 \mu \mathrm{m}$, intermediate $1.72 \mu \mathrm{m}$ and ultra-rapid $1.71 \mu \mathrm{m})$, as was the 
tenderness. Weight loss for the ultra-rapid regime was significantly reduced compared to the conventional regime $(0.57 \%$ as opposed to $1.48 \%)$. However, relative humidity was too high (100\%) during temperature equilibration (holding at $4^{\circ} \mathrm{C}$ after $3.5 \mathrm{~h}$ of chilling) and carcasses became visibly wet. In conclusion ultra-rapid chilling of lamb carcasses can yield substantial reductions in evaporative weight loss (although relative humidity must not be excessive after chilling) as well as a reduction in chilling time, without increasing the toughness of the loins.

\section{Use of low voltage stimulation}

The $\mathrm{pH}$ of the loin muscle (M. longissimus dorsi) at 1 and $4 \mathrm{~h}$ after slaughter was lower in ES than in non-ES carcasses, irrespective of chilling treatment ( $P$ $<0.001)$. By $24 \mathrm{~h}$ these differences in $\mathrm{pH}$ were not present

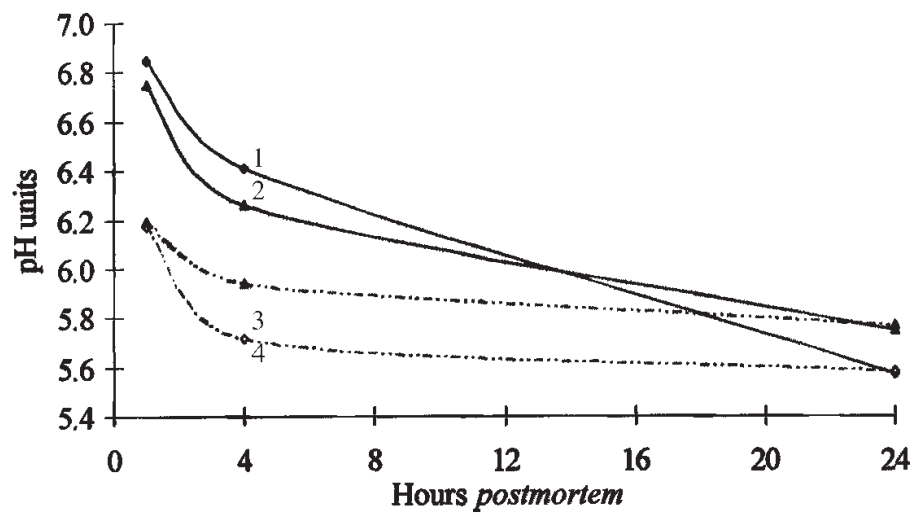

Figure 1. The effect of chilling regime and electrical stimulation on the $\mathrm{pH}$ of lamb loins (M. longissimus dorsi).

$1=$ Chilled conventionally at $4{ }^{\circ} \mathrm{C}$ and not electrically stimulated

$2=$ Ultra-rapid chilled at $-20^{\circ} \mathrm{C}$ and not electrically stimulated

$3=$ Ultra-rapid chilled at $-20^{\circ} \mathrm{C}$ and electrically stimulated

$4=$ Chilled conventionally at $4^{\circ} \mathrm{C}$ and electrically stimulated 
Electrical stimulation had no effects on the tenderness of leg muscles (Figure 2). In loins (M. longissimus dorsi), electrically stimulated carcasses produced more tender meat than non-stimulated carcasses on day $1(\mathrm{P}<0.01)$. Ageing improved tenderness and on day 5 there was no difference between treatments.

When ranked in order of toughness, carcasses that did not receive electrical stimulation (ultra-rapidly chilled ones in particular) tended to be tougher than those that did receive it. Two out of forty non-stimulated M. longissimus dorsi (one ultra-rapidly chilled and one conventionally chilled) and two out of forty M. semimembranosus (both ultra-rapidly chilled) were considered slightly tough (i.e. shear force $>45$ Newtons) on day 5. However, mean shear forces on day 5 were below 40 Newtons which is considered tender.

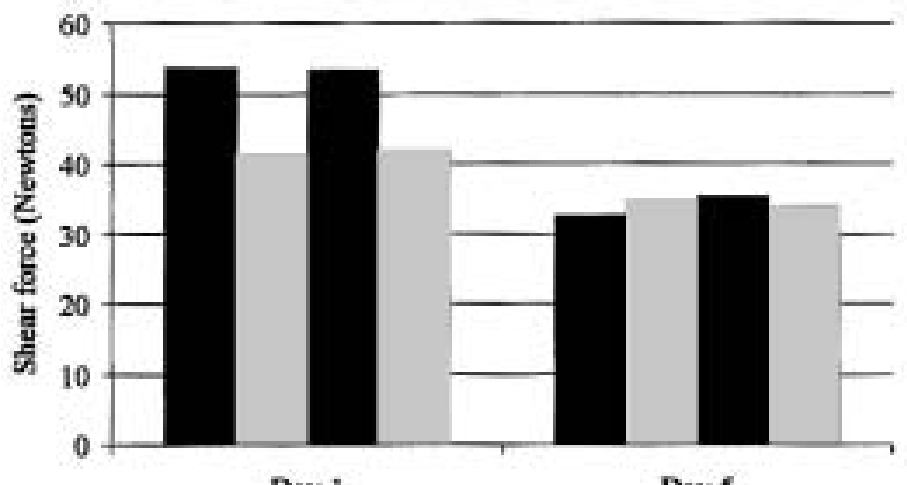

Day 1

Day 5

Figure 2. The effect of ultra-rapid chilling and electrical stimulation on the tenderness of lamb loins (M.longissimus dorsi).

In conclusion, ultra-rapid chilling of lamb carcasses produced meat from leg and loin muscles as tender as that from conventionally chilled carcasses. Electrical stimulation improved meat tenderness initially and, more importantly, eliminated the problem of occasional tough carcasses. In the absence of electrical stimulation, the occurrence of occasional tough carcasses would inhibit the use of ultra-rapid chilling on an industrial scale. 


\section{Optimisation of the ultra-rapid chilling process}

Twelve variations of low temperature and airspeed were examined to determine the most favourable regime in terms of weight loss and meat tenderness.

Table 2. The effect of low temperatures and airspeed on weight loss and tenderness of loins in lamb carcasses

\begin{tabular}{|c|c|c|c|}
\hline & & Weight loss & $\begin{array}{l}\text { Shear force of loins } \\
\text { (Newtons) }\end{array}$ \\
\hline & & Day 1 & Day 5 \\
\hline conventional $\left(4^{\circ} \mathrm{C}, 0.2 \mathrm{~m} / \mathrm{s}\right)$ & 1.80 & 62.9 & 38.8 \\
\hline $\mathrm{A}\left(-10^{\circ} \mathrm{C}, 1.5 \mathrm{~m} / \mathrm{s}, 2.5 \mathrm{~h}\right)$ & 1.60 & 60.5 & 38.9 \\
\hline $\mathrm{B}\left(-25^{\circ} \mathrm{C}, 1.5 \mathrm{~m} / \mathrm{s}, 2.5 \mathrm{~h}\right)$ & 1.50 & 78.1 & 42.6 \\
\hline $\mathrm{C}\left(-20^{\circ} \mathrm{C}, 1.5 \mathrm{~m} / \mathrm{s}, 3.5 \mathrm{~h}\right)$ & 1.15 & 87.6 & 54.5 \\
\hline $\mathrm{D}\left(-10^{\circ} \mathrm{C}, 1.5 \mathrm{~m} / \mathrm{s}, 3.5 \mathrm{~h}\right)$ & 1.22 & 91.5 & 55.0 \\
\hline $\mathrm{E}\left(-20^{\circ} \mathrm{C}, 0.5 \mathrm{~m} / \mathrm{s}, 3.5 \mathrm{~h}\right)$ & 1.41 & 99.3 & 63.0 \\
\hline $\mathrm{F}\left(-20^{\circ} \mathrm{C}, 1.5 \mathrm{~m} / \mathrm{s}, 2.5 \mathrm{~h}\right)$ & 1.47 & 84.3 & 47.3 \\
\hline $\mathrm{G}\left(-10^{\circ} \mathrm{C}, 0.5 \mathrm{~m} / \mathrm{s}, 2.5 \mathrm{~h}\right)$ & 2.01 & 72.0 & 40.0 \\
\hline $\mathrm{H}\left(-10^{\circ} \mathrm{C}, 0.5 \mathrm{~m} / \mathrm{s}, 3.5 \mathrm{~h}\right)$ & 1.50 & 74.4 & 47.7 \\
\hline $\mathrm{I}\left(-20^{\circ} \mathrm{C}, 0.5 \mathrm{~m} / \mathrm{s}, 2.5 \mathrm{~h}\right)$ & 1.36 & 74.9 & 45.7 \\
\hline $\mathrm{J}\left(-25^{\circ} \mathrm{C}, 1.5 \mathrm{~m} / \mathrm{s}, 3.5 \mathrm{~h}\right)$ & 1.01 & 78.1 & 54.5 \\
\hline $\mathrm{K}\left(-25^{\circ} \mathrm{C}, 0.5 \mathrm{~m} / \mathrm{s}, 2.5 \mathrm{~h}\right)$ & 1.26 & 99.2 & 51.7 \\
\hline $\mathrm{L}\left(-25^{\circ} \mathrm{C}, 0.5 \mathrm{~m} / \mathrm{s}, 3.5 \mathrm{~h}\right)$ & 1.04 & 93.9 & 55.0 \\
\hline
\end{tabular}


Weight loss ranged from $1.01 \%$ to $2.01 \%$ and results show that 10 of the 12 experimental regimes had significantly lower weight losses than the conventional chilling regime. The regime with the lowest weight losses (regime J) was the most severe of all the chilling regimes. The two experimental regimes that did not differ from conventional chilling were A \& G. Both of these regimes used the highest temperatures $\left(-10^{\circ} \mathrm{C}\right)$ and had only $2.5 \mathrm{~h}$ of ultra-rapid chilling prior to the equilibration phase. Regime A had an airspeed of $1.5 \mathrm{~m} / \mathrm{s}$ and weight losses were lower than the conventional regime by $0.2 \%$. The other regime $(\mathrm{G})$ had an airspeed of 0.5 $\mathrm{m} / \mathrm{s}$ which made this the least severe regime and the only regime to have weight losses higher than those of the conventional regime $(2.01 \%$ compared to $1.80 \%$ ). It was apparent that as ultra-rapid chilling became less severe the carcasses did not have the required reservoir of cold to promote weight gain from moisture condensation during the equilibrium phase of chilling and so weight losses were more prominent.

Regime A produced meat as tender as conventional chilling. The weight loss of this regime was not as high as the conventional regime with differences bordering on significance. Regime J had the lowest weight losses (1.01\%) but had unacceptably high shear values in the loins. In conjunction with electrical stimulation, to counteract the cold toughening, this may be the most commercially viable regime. Given that the costs of ultra-rapid chilling are three times that of conventional chilling (Bowater, 1986) and the cost of $1 \%$ evaporative weight loss is fifty times that of the energy costs of chilling (Honikel, 1998), significant savings can be made by using ultra-rapid chilling rather than conventional chilling.

\section{Effect of method of stunning on meat $\mathrm{pH}$ values}

The $\mathrm{pH}$ of meat affects its colour, tenderness and cooking loss. The postmortem $\mathrm{pH}$ decline of lamb loin (M. longissimus dorsi) was measured to investigate how it is affected by electrical stunning compared to captive bolt stunning. There was no difference between the $\mathrm{pH}$ of these groups at any time postmortem. Stunning method did not cause a consistent change in either $\mathrm{pH}$ values or the rate of $\mathrm{pH}$ decline. 


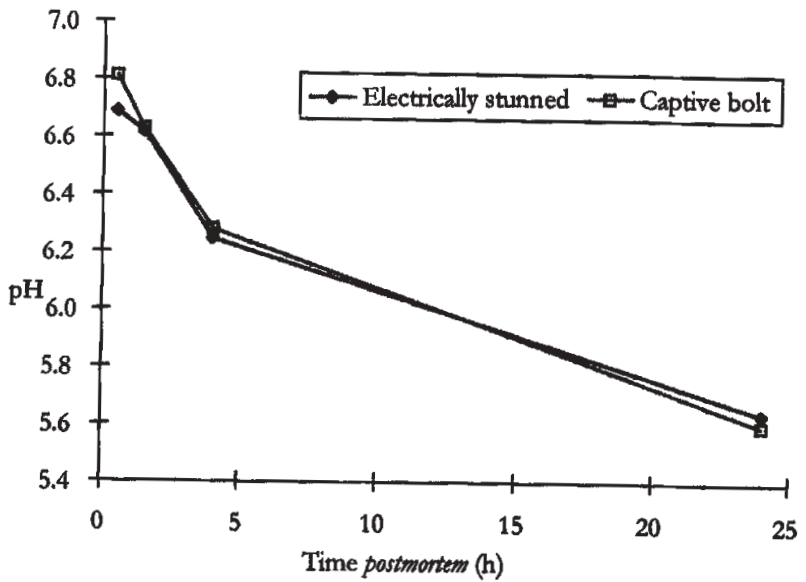

Figure 3. The effect of stunning method on the $\mathrm{pH}$ of lamb loins ( $M$. longissimus dorsi).

However, there was a wide range of $\mathrm{pH}$ values in lambs stunned by both techniques, even as early as $0.5 \mathrm{~h}$ postmortem, indicating that other factors cause $\mathrm{pH}$ variability in lamb M.longissimus dorsi.

\section{Effects of age, weight and season on meat pH values}

Several factors affect the rate of $\mathrm{pH}$ decline and these are known to include stress, electrical stimulation and chilling temperature. However these factors alone do not account for the variability that occurs in the rate of postmortem $\mathrm{pH}$ decline. Other factors are known to affect the rate of $\mathrm{pH}$ fall, these include breed, sex, season and possibly age.

The tenderness of meat which has been ultra-rapidly chilled is known to be influenced by favourable meat $\mathrm{pH}$ conditions. If $\mathrm{pH}$ is too high in the early hours postmortem, then cold-shortening can occur, causing toughening of the meat. The occurrence of occasional cold-shortened carcasses under ultrarapid chilling conditions can be avoided by applying electrical stimulation to all carcasses. A potential problem exists with this approach. The $\mathrm{pH}$ of 
already fast glycolysing carcasses can be lowered too quickly resulting in a decline in tenderness (Marsh et al., 1987; Smulders et al., 1990; Pike et al., 1993), although this has not been reported in ultra-rapidly chilled carcasses. In order to better understand $\mathrm{pH}$ behaviour in lambs, this experiment was carried out to determine whether factors such as age, weight, season, sex and ambient conditions influence the rate and extent of postmortem $\mathrm{pH}$ decline. Regression analysis of these factors could make it possible to predict $\mathrm{pH}$ fall in lamb and thereby estimate the individual electrical requirements of each lamb to give optimum $\mathrm{pH}$ fall.

A wide range of $\mathrm{pH}$ values was found in the 96 lambs from $0.5 \mathrm{~h}$ to $24 \mathrm{~h}$ after slaughter. Once again this shows the inherent variable nature of postmortem $\mathrm{pH}$ fall in lamb. The rate of $\mathrm{pH}$ fall in female lambs was faster than in male lambs for the first 4 hours postmortem $(\mathrm{P}<0.05)$. Ultimate $\mathrm{pHs}$ were not different.

Table 3: Carcass pH values in loins ( $\mathrm{M}$. longissimus dorsi) of male and female lambs chilled at $4^{\circ} \mathrm{C}$

\begin{tabular}{|lccccc|}
\hline & & $\mathbf{0 . 5}$ hours & $\mathbf{1 . 5}$ hours & $\mathbf{4}$ hours & $\mathbf{2 4}$ hours \\
\hline Sex & $\mathbf{n}$ & $\mathbf{p H}$ & $\mathbf{p H}$ & $\mathbf{p H}$ & $\mathbf{p H}$ \\
\hline Female & 48 & $6.66(6.36-7.00)$ & $6.47(6.08-6.87)$ & $6.22(5.79-6.56)$ & $5.51(5.31-5.87)$ \\
\hline Male & 48 & $6.73(6.37-6.91)$ & $6.60(6.07-6.87)$ & $6.40(5.80-6.75)$ & $5.52(5.31-5.76)$ \\
\hline All & 96 & $6.70(6.36-7.00)$ & $6.53(6.07-6.87)$ & $6.31(5.79-6.75)$ & $5.52(5.31-5.87)$ \\
\hline
\end{tabular}

Mean $\mathrm{pH}$ values are given, with range of values in brackets

Regression analyses of $0.5 \mathrm{~h} \mathrm{pH}$, lamb age, carcass weight and ambient temperature were performed to find the best-fit models to use for the prediction of subsequent $4 \mathrm{~h} \mathrm{pH}$ (Table 4). Individual models for the male and female populations were more accurate than combined models. Animal age was of little benefit in the combined (all) prediction models. When data 
was divided into male and female groups, the equations improved dramatically and animal age now had some benefit as a predictor.

Table 4. Summary statistics for best-fit models for the prediction of $4 \mathrm{~h}$ $\mathrm{pH}$ in lamb carcasses using various $0.5 \mathrm{~h}$ measurements

\begin{tabular}{|c|c|c|c|c|c|c|}
\hline \multirow[b]{2}{*}{ Variable } & \multicolumn{2}{|c|}{ all $(n=96)$} & \multicolumn{2}{|c|}{ male $(n=48)$} & \multicolumn{2}{|c|}{ female $(n=48)$} \\
\hline & $\mathrm{R}^{2}$ & R.S.D. & $\mathrm{R}^{2}$ & R.S.D. & $\mathrm{R}^{2}$ & R.S.D. \\
\hline $0.5 \mathrm{~h} \mathrm{pH}$ & 0.681 & 0.124 & 0.715 & 0.118 & 0.699 & 0.118 \\
\hline $0.5 \mathrm{~h} \mathrm{pH}$, age & 0.681 & 0.125 & 0.737 & 0.113 & 0.705 & 0.118 \\
\hline $0.5 \mathrm{~h} \mathrm{pH},{ }^{\circ} \mathrm{C}$ & 0.685 & 0.124 & 0.716 & 0.117 & 0.717 & 0.115 \\
\hline $0.5 \mathrm{~h} \mathrm{pH}$, age, ${ }^{\circ} \mathrm{C}$ & 0.688 & 0.124 & 0.737 & 0.114 & 0.770 & 0.105 \\
\hline $0.5 \mathrm{~h} \mathrm{pH}$, weight & 0.719 & 0.117 & 0.736 & 0.113 & 0.736 & 0.111 \\
\hline 0.5h $\mathrm{pH}$, weight, age & 0.730 & 0.116 & 0.798 & 0.100 & 0.737 & 0.112 \\
\hline $0.5 \mathrm{~h} \mathrm{pH}$, weight, ${ }^{\circ} \mathrm{C}$ & 0.740 & 0.113 & 0.764 & 0.108 & 0.786 & 0.101 \\
\hline $0.5 \mathrm{~h} \mathrm{pH}$, weight, age, ${ }^{\circ} \mathrm{C}$ & 0.740 & 0.114 & 0.801 & 0.100 & 0.801 & 0.099 \\
\hline
\end{tabular}

In conclusion, the important factors are sex, carcass weight, and to a lesser degree, age and ambient temperature. Given the wide range of $\mathrm{pH}$ values in the early hours ( $4 \mathrm{~h}$ ) postmortem (Table 3 ), the application of ultra-rapid chilling could be expected to produce cold shortening and toughening in some carcasses. The application of electrical stimulation eliminates this possibility but introduces the potential problem of excessively fast $\mathrm{pH}$ fall resulting in toughened carcasses. However, by using the $4 \mathrm{~h} \mathrm{pH}$ prediction models (based on $0.5 \mathrm{~h} \mathrm{pH}$, ambient temperature, sex, weight and age), it is possible to identify the electrical stimulation requirements of each lamb carcass and thus avoid the possibility of both cold shortening and excessively 
fast $\mathrm{pH}$ fall. A $\mathrm{pH}$ meter $\left(\mathrm{pH}^{*} 21\right)$ for use on meat carcasses in abattoirs has recently been developed to eliminates the problems associated with $\mathrm{pH}$ measurement in this environment (NWK binär GmbH, Landsberg, Germany).

Its automatic recording facility enables this meter to be used in conjunction with a $\mathrm{PC}$ to process $\mathrm{pH}$, weight and sex of each animal and automatically predict $\mathrm{pH}$ at $4 \mathrm{~h}$. This approach would go a long way towards eliminating meat tenderness variability.

\section{CONCLUSIONS}

- Ultra-rapid chilling can be used to chill lamb carcasses without adversely affecting the quality of the meat. However, tough carcasses can also be produced if the rate of $\mathrm{pH}$ fall is too slow and therefore electrical stimulation should be used to safeguard against this

- Intermediate $\mathrm{pH}$ fall produces tender meat, with the necessity of no more than $24 \mathrm{~h}$ ageing, under any chilling circumstances.

- By careful control of relative humidity during the second stage of chilling, reductions of $1 \%$ in evaporative weight losses can be achieved.

- Variation in the rate of fall of lamb loin $\mathrm{pH}$ after slaughter affects meat tenderness, but this is not due to the method of stunning or to seasonal factors. The sex of the lambs does affect the rate of meat $\mathrm{pH}$ decline early postmortem. 
List of publications from this research project

Mc Geehin, B., Sheridan, J.J., Butler, F. 1995. Ultra-rapid chilling of lamb carcasses. Irish Journal of Agricultural \& Food Research, 34, (2): 208-209.

Mc Geehin, B., Sheridan, J.J., Butler, F 1996. The use of ultra-rapid chilling and electrical stimulation on lamb carcasses. Proceedings of 42nd International Congress of Meat Science and Technology, Lillehammer, Norway, M-2, 506-507.

Sheridan, J.J., Mc Geehin, B., Butler, F. 1998. The use of ultra-rapid chilling and electrical stimulation on lamb carcasses. In: Very fast chilling in beef Vol.1. Peri-mortem and the chilling process, Published by University of Bristol Press, EC Concerted Action CT 94-1881, pp. 55-60.

Mc Geehin, B., Sheridan, J.J., Butler, F The effect of stunning method on the $\mathrm{pH}$ of lamb. Developments in Chemical Engineering and Mineral Processing (in press).

Mc Geehin, B., Sheridan, J.J., Butler, F. Further investigation on the ultrarapid chilling of lamb carcasses. Journal of Muscle Foods (in press).

Sheridan, J.J., Mc Geehin, B., Butler, F. The effect of ultra-rapid chilling and electrical stimulation on the tenderness of lamb carcass muscles. Journal of Muscle Foods (in press). 


\section{REFERENCES}

1. Bowater, F.J. 1986. The economics of modern beef chilling systems. In: Recent advances and developments in the refrigeration of meat by chilling. Institute of Refrigeration, Commission C2, Paris. pp. 165-170.

2. Devine, C.E., Ellery, S., Wade, L., and Chrystall, B.B. 1984. Differential effects of electrical stunning on the early post-mortem glycolysis in sheep. Meat Science, 11, (4): 301-309.

3. Honikel, K.O. 1998. Conclusion and executive summary. In: Very fast chilling in beef Vol.1. Peri-mortem and the chilling process, Published by University of Bristol Press, EC Concerted Action CT 94-1881, pp. 153-157.

4. Marsh, B.B., Ringkob, T.P., Russell, R.L., Swartz, D.R., and Pagel, L.A. 1987. Effects of early-postmortem glycolytic rate on beef tenderness. Meat Science 21, (4): 241-248.

5. Pike, M.M., Ringkob, T.P., Beekman, D.D., Koh, K.C., and Geerthoffer, W.T. 1993. Quadratic relationship between early-postmortem glycolytic rate and beef tenderness. Meat Science 34, (1): 13-26.

6. Sheridan, J.J. 1990. The ultra-rapid chilling of lamb carcasses. Meat Science, 28, (1): 31-50.

7. Smulders, F.J.M., Marsh, B.B., Swartz, D.R., Russell, R.L. \& Hoenecke, M.E. 1990. Beef tenderness and sarcomere length. Meat Science, 28, (4): 349-363. 


\section{The National Food Centre}

RESEARCH \& TRAINING FOR THE FOOD INDUSTRY Dunsinea, Castleknock, Dublin 15, Ireland.

Telephone: (+353 1) 8059500

Fax: (+353 1) 8059550 